\title{
A comprehensive review of intracranial aneurysm and comparison between different treatment to the disease
}

\author{
Ningquan Zhang ${ }^{1 *}$ \\ ${ }^{1}$ Shanghai Pinghe school, Shanghai, 200000, China
}

\begin{abstract}
An intracranial aneurysm is an abnormal protrude in the intracranial arteries' wall, which is the primary cause of hemorrhagic arachnoid. It is the third cerebrovascular disease besides cerebral thrombosis and hypertensive cerebral hemorrhage. There are many methods of treating intracranial aneurysms. Different methods have different outcomes and have their own advantages and drawbacks. This review provides comprehensive information on intracranial aneurysms and focuses on the comparison of different clinical methods treating this disease. Given the significant health concern of intracranial aneurysms, more attention should be paid, and innovative treating methods would be reasonably expected.
\end{abstract}

\section{Introduction}

\subsection{Associated disorder}

The most well-known inherited disorder related to the intracranial saccular aneurysm is Autosomal dominant polycystic kidney disease [1-4]. Multiple endocrine neoplasia type I [5], hereditary hemorrhagic telangiectasia [6], Ehlers-Danlos syndrome type IV [7], Marfan's syndrome [8], and neurofibromatosis type I [9] are also related diseases of intracranial aneurysm. The increasing occurrence of aneurysms in the brain has also been associated with moyamoya disease [10], intracranial arteriovenous malformations [11], sickle-cell disease [12], systemic lupus erythematosus [13], fibromuscular dysplasia [14], and coarctation of the aorta [15].

\subsection{Location of the aneurysm}

The aneurysms can locate in different sites over the whole body. The internal carotid artery, the anterior communicating artery to anterior cerebral artery junction, the middle cerebral artery branch points, the ophthalmic artery origin, and the internal carotid artery bifurcation are the frequently occurred sites of intracranial aneurysm. In the vertebrobasilar distribution, the tip of the basilar artery, the superior cerebellar artery branch from the basilar artery, the anterior inferior cerebellar artery branch from the basilar artery, and the posterior inferior cerebellar artery branch from the vertebral artery are the most common sites.

The patients that have ruptured intracranial aneurysms are likely to have multi-onset of aneurysms [16]. Some patients, about $20 \%$, will have more than one aneurysm lesion [17].

\subsection{Risk factors}

The commonly applied risk factors in aneurysm related disease detection are summarized below as:

- Untreatable factors: sex, old age, and genetic factors.

- Treatable factors: smoking $[18,19]$, heavy alcohol use $[18,20,21]$, hypertension $[19,20,22]$ and drug use including cocaine and high dose of estrogen [23-25].

- Associated factors: low BMI (still not very clear) [26].

\section{Epidemiology of aneurysm}

\subsection{Distribution of intracranial aneurysm.}

\subsubsection{Distribution in regions and countries.}

Intracranial saccular aneurysms are also called berry aneurysms because their special appearance is one of the intracranial aneurysms, and they are like to occur in 1$2 \%$ of the population $[27,28]$ and cause about $80-85 \%$ of non-traumatic subarachnoid hemorrhages [29].

The overall occurrence of intracranial saccular aneurysms in human bodies is about 3.2\% [30]. It is suggested that the prevalence of intracranial saccular aneurysms in the whole population is about $0.5-3 \%$, from the findings of some imaging devices like arteriography and MRI [31,32]. About $1.8 \%$ of adult participants have an aneurysm detected by screening MRI in European countries [33]. In a typical study of the Chinese population [34], 7\% of middle-aged to old aged adults (35 to 75 years old) had aneurysms detected by brain magnetic resonance angiography (MRA). In Norway, the frequency of intracranial saccular aneurysms was $1.9 \%$, detected

${ }^{*}$ Corresponding author: *zhangningquan@shphschool.com 
by MRA. The occurrence of subarachnoid haemorrhage in Norway, the same participants, was 16.4 per 100000 people per year [35].

\subsubsection{Distribution in sex and age}

Women are more likely to have unruptured intracranial aneurysms than men. As reported by the case study with a large number of participants, the ratio of aneurysms onset for women to men is about 3:1 [36, 37]. Furthermore, unruptured intracranial aneurysms also occur more frequently in elderly people than in young people [38], especially rare among children $[39,40]$. In comparison with children patients, aneurysms in adults are likely to occur in the posterior circulation (40-45\%) and in the female group (onset ratio with female patients and male patients has been estimated to be $2: 1$ ) $[39,40]$.

\subsection{The Genetic factor of intracranial aneurysm}

In most conditions, if an intracranial aneurysm occurs in people s first-degree relatives, they might have a smaller chance of suffering from intracranial aneurysms.

- There is an investigation of patients that have subarachnoid haemorrhage, only $9.4 \%$ of them have a first-degree relative that has subarachnoid haemorrhage or intracranial aneurysm, and $14 \%$ of them have a second-degree relative that suffer from those diseases.

- 193 patients' relatives underwent a screening study with subarachnoid haemorrhage aged from 20 to 70 years $[41,42]$. The prevalence of first-degree relatives is only about $4 \%$ that had an unruptured intracranial aneurysm screening by MRA and intra-arterial angiography.

- When screening the first-degree relatives of patients with MRA to determine whether the occurrence of an intracranial aneurysm, if two or more members in a family once suffered from subarachnoid haemorrhage or intracranial aneurysm, the occurrence of having the diseases is the highest $[43,44]$. The prevalence of intracranial aneurysm that depends on age among firstdegree relatives was about $9.2 \%$ in the population that is over 30 if a family has more than two intracranial aneurysm patients.

\subsection{Time of finding the intracranial aneurysm.}

Half of the aneurysms are found after subarachnoid haemorrhage [45], which can occur in 6-10 per 100000 people per year.

\subsection{Rupture rate of intracranial aneurysm}

- There is an 8.3 years study with 130 intracranial aneurysm patients [46, 47]. If the aneurysms' diameter is less than $10 \mathrm{~mm}$, the aneurysmal rupture will not occur at all. However, among 51 patients with $10 \mathrm{~mm}$ or larger aneurysms, 15 of them suffered from a ruptured aneurysm. The frequency of rupture was $3.3 \%$ per year for aneurysms that are $10-15 \mathrm{~mm}$ diameter, the risk of rupture for aneurysms that are 16-25 mm diameter is about $5.6 \%$ per year, and the aneurysms that are larger than $25 \mathrm{~mm}$ in diameter have the prevalence of rupture being $8.9 \%$ per year.

- In a cohort of 142 patients, 27 hemorrhages occurred, again with aneurysm size being a key predictor of subarachnoid haemorrhage [47]. Patients were followed up for a mean of 19.7 years [48]. The annual risk of subarachnoid haemorrhage for aneurysms less than $10 \mathrm{~mm}$ in diameter was $1.1 \%$ per year, and for those $10 \mathrm{~mm}$ in diameter or greater, the rupture risk was $2.8 \%$ per year. Cigarette smoking was anthorpredictor of haemorrhage. Follow-up was subsequently extended to a median of 21 years. The mean annual incidence of rupture in this cohort was $1.1 \%$ per year. In the extended follow-up [48-50], cigarette smoking, anterior communicating artery location, and aneurysm diameter $7 \mathrm{~mm}$ or less were predictors of haemorrhage. On the other hand, age was inversely associated with haemorrhage. There were no ruptures after 25 years of follow-up.

- The International Study of Unruptured Intracranial Aneurysms (ISUIA)published retrospective data for patients without a history of subarachnoid haemorrhage and patients with a history of subarachnoid haemorrhage (727 to 722) [37]. There is a larger rupture rate which was $0.5 \%$ per year, for patients that has a previous experience of subarachnoid haemorrhage than those who do not have a history of subarachnoid haemorrhage, if the size of aneurysms is less than $10 \mathrm{~mm}$ in diameter.

- During a 3-year retrospective study, there are 49 of 62 untreated patients have less than $5 \mathrm{~mm}$ in diameter of unruptured intracranial aneurysms [1]. The hemorrhages happened in 7 examples, and $0.9 \%$ per year was the occurrence of rupture in patients that have aneurysms less than $10 \mathrm{~mm}$ in diameter. If patients' aneurysms are larger than $10 \mathrm{~mm}$ in diameter in size, $6.7 \%$ per year is the frequency of rupture. 
Table 1. The summary of the different studies on intracranial aneurysm

\begin{tabular}{|c|c|c|c|c|c|c|c|}
\hline $\begin{array}{c}\text { Study of } \\
\text { patients }\end{array}$ & $\begin{array}{c}\text { Study } \\
\text { time } \\
\text { (years) }\end{array}$ & $\begin{array}{c}\text { Rupture risk } \\
\text { per year for } \\
<\mathbf{1 0} \mathbf{~ m m} \\
\text { aneurysm }\end{array}$ & $\begin{array}{c}\text { Rupture risk } \\
\text { per year } \\
\text { for } \mathbf{1 0} \mathbf{~} \mathbf{m m} \\
\text { aneurysm }\end{array}$ & $\begin{array}{c}\text { Rupture risk } \\
\text { per year for } \\
\mathbf{1 0 - 1 5} \mathbf{~ m m} \\
\text { aneurysm }\end{array}$ & $\begin{array}{c}\text { Rupture risk } \\
\text { per year for } \\
\mathbf{1 6 - 2 5} \mathbf{~ m m} \\
\text { aneurysm }\end{array}$ & $\begin{array}{c}\text { Rupture risk } \\
\text { per year } \\
\text { for } \mathbf{2 5} \mathbf{~ m m} \\
\text { aneurysm }\end{array}$ & Affecting factors \\
\hline 130 & 8.3 & $0 \%$ & NA & $3.3 \%$ & $5.6 \%$ & $8.9 \%$ & $\begin{array}{c}\text { Size of aneurysm; } \\
\text { patients' age } 4647\end{array}$ \\
\hline 142 & 21 & $1.1 \%$ & $2.8 \%$ & NA & NA & NA & $\begin{array}{c}\text { Aneurysm's size; } \\
\text { Cigarette smoking; } \\
\text { anterior } \\
\text { communicating } \\
\text { artery location; age }\end{array}$ \\
\hline 1449 & NA & $\begin{array}{c}0.5 \% \text { (have the } \\
\text { history of } \\
\text { hemorhage) }\end{array}$ & $0.7 \%$ & NA & NA & NA & The history of \\
haemorrhage
\end{tabular}

\section{Diagnostic method}

\subsection{CT\&MRI}

They can identify possible aneurysms.

\subsection{MRA\&CTA}

The occurrence and location of the aneurysm are usually found by these two devices, and they are still improving. The morphological data is offered, and they are becoming more and more sensitive. For aneurysm detection, now they can detect aneurysms that are $4 \mathrm{~mm}$ or less in diameter.

\subsection{Cerebral angiogram}

The details of aneurysms are often clearly shown by the cerebral angiogram.

\section{Therapies}

\subsection{First-generation of Pipeline Embolization Device (PED)}

Parent vessel is the place where flow diverter normally implanted by covering the neck of aneurysms to change the hemodynamics, and then the inflow rate into the sac of aneurysms is reduced. As a result, thrombosis and occlusion of aneurysms can form [51, 52].

\subsection{Second-generation of Derivo Embolization Device (DED)}

Basic principles are similar to PED. However, the fluoroscopic visibility, flexible delivery system, and surface finishing (BlueXide) have been improved to reduce thrombogenicity $[53,54]$.

\subsection{Super Evolve flow diverter (SE)}

This is the latest method of treating the intracranial aneurysm. SE allows exclusion of the aneurysm from blood circulation without controlling intrasaccular by changing the direction of blood flow in the parent artery that is away from the aneurysm. Therefore, aneurysm thrombosis and reconstruction of the diseased artery segment can be formed [55].

\section{Comparing method}

The PED and DED will be compared and evaluated, respectively, and then the SE will be evaluated solely.

The PED and DED will be compared on three aspects: procedural adverse events (Hemorrhagic and thromboembolic events), rate of symptomatic complications (neurologic worsening), patients' own experience, procedure-related morbidity (neurologic worsening), and angiographic outcome (complete aneurysm occlusion and favorable occlusion) with the 6-month follow up.

The SE flow diverter will be evaluated through the aspects of samples' conditions (aneurysmal characteristics), complications, and clinical outcome.

\section{PED VS DED}

\subsection{Samples' condition}

In the reported study, there was a total number of 111 patients. PED was used in 62 of them, and the rest of them were treated by DED. For the PED group, many patients were implanted by PED many times because of different or recurrent aneurysms. The number of women was far more than the number of men in the PED group $(89 \%)$ than in the DED group (84\%), but the difference in age was small.

The likelihood of recurrence of aneurysms was greater in the PED group (34.2\%) than that in the DED group 
$(14.3 \%)$. There were more fusiform aneurysms in the DED group (12.2\%) than in the PED group (1.4\%). Overall, the size of aneurysms was larger in the DED group $(11.3 \mathrm{~mm}$ in diameter to $14.9 \mathrm{~mm}$ in diameter) than in the PED group $(7.5 \mathrm{~mm}$ in diameter to $5.9 \mathrm{~mm}$ in diameter). Fortunately, the difference was not statistically significant (P 1/4 0.098).

\subsection{Procedural adverse events (Hemorrhagic and thromboembolic events)}

The comprehensive adverse event rate was comparable between both groups (PED: 5.4\%, DED: $8.2 \%, \mathrm{P} 1 / 4$ 0.713) according to the article [56]. Both the PED group and DED group have 3 cases that have occurred thromboembolic phenomenon, which was $4.1 \%$ risk of occurrence in the 62 patients PED group and $6.1 \%$ in the 39 patients DED group.

\subsection{Rate of symptomatic complications (neurologic worsening), patients' own experience, and Procedural-related morbidity}

There are a total number of 4 patients (3.2\%) who developed ischemic stroke. Both the PED group and DED group have two cases, and the frequency was $2.7 \%$ in the PED group and $4.1 \%$ in the DED group. After 6 months' further research, there was no more morbidity. Consequently, the procedure-related morbidity rate was $2.7 \%$ in the PED group and $4.1 \%$ in the DED group.

\subsubsection{PED group}

An intradural aneurysm of the right internal carotid artery occurred in the first patient in the PED group. A serious in-stent thrombosis was exhibited by the scanning of computed tomography angiography. Then 2 overlapping PEDs were implanted in patient's vessel, but the patient's right leg suffered from minor paresis. In the center cerebral artery, there were some penetrate embolic infractions detected by magnetic resonance imaging. After 6 months, the patient recovered.

The other patient treated by PED suffered from an intradural left-sided internal carotid artery aneurysm. Unlike the first one, the patient got minor right-sided hemiparesis after implanting the PED. The thromboembolic complications did not show initially by using the digital subtraction angiography. However, many foci of thromboembolic infarctions existed. These were detected by magnetic imaging. After 6 months' observation, the patients became almost asymptomatic.

\subsubsection{DED group}

The thrombus formed in the 2 patients treated by DED at the surface of the flow diverter during the process of treatment, and then it was successfully dissolved by immediate intra-arterial tirofiban administration. However, both patients exhibited postinterventional motoric aphasia, and small infarction was detected by computed tomography. Aphasia was cured fully in the first patient, but it was resolved in the second patient after 30 days of treatment.

\subsection{Angiographic outcome}

After 6 months observation, complete aneurysm occlusion (OKM D) was reached in $72.6 \%$ of PED cases and $62.5 \%$ of DED cases, and favorable occlusion (OKM CpD) was $79.0 \%$ and $80.0 \%$ in each group.

\section{SE flow diverter}

\subsection{Samples' condition}

SE flow diverter was implanted in 42 patients, and the study sustained 14 months [57].

Normally the SE flow diverter was used in a wide necked aneurysm with neck $\geq 4 \mathrm{~mm}$ or a dome/neck ratio $\leq 2$, blister-like or fusiform aneurysms. Whether the aneurysms are ruptured or unruptured, located in the anterior or posterior circulation, pretreated, or did not pretreat, the SE flow diverter can treat all these aneurysms. However, if the patients use other types of flow diverters during the study, their data was excluded from the research.

Overall, 42 patients with 46 intracranial aneurysms were treated by SE flow diverters for 14 months. The median age of patients was 58 years, and the range of patients' age was from 28 to 84 years. The aneurysm size was $6.6 \mathrm{~mm}$ in diameter in median (IQR 4.0-12.2 $\mathrm{mm}$ ) with a median neck width of $4 \mathrm{~mm}$ (IQR 2.2-5.4 mm). About $26 \%$ of aneurysms were $\geq 10 \mathrm{~mm}$ (12/46), and about 85\% (39/46) patients' aneurysms presented a dome/neck ratio $\leq 2$. In the overall shape, $65 \%(30 / 46)$ aneurysms were saccular, $22 \%(10 / 46)$ were fusiform, $9 \%(4 / 46)$ were blister, and 4\% (2/46) were dissecting aneurysms. The anterior circulation was the place where about $89 \%$ aneurysms (41/46) occurred, and about $13 \%$ (6/46) aneurysms exhibited the baseline subarachnoid hemorrhage.

\subsection{Complications}

About $2 \%$ of (1/42) patients had a complication. During the procedure, two SE flow diverters were implanted into a large, non-ruptured fusiform paraophthalmic internal carotid aneurysm (ICA). The platelet inhibition was successful when doctors did the baseline testing, but on the final angiogram, an acute in-stent thrombosis was exhibited. Then it was resolved completely by thromboaspiration. The patient was asymptomatic after the treatment. However, the in-stent thrombosis reoccurred two weeks later. As a result, a further thrombectomy procedure is needed.

There were several moderate neurological complications that occurred in about $10 \%$ (4/42) patients: three people showed punctuate infarctions when scanning by MRI, but they did not present any neurological symptoms, and one patient had a headache for 3 weeks due to 
the treatment of large aneurysm of the paraophthalmic ICA.

\subsection{Clinical outcome}

The mortality in the hospital was $2 \%$, which means one patient died. The subarachnoid hemorrhage occurred in one patient on admission due to bilateral ICA. Since the initial place of bleeding could not be successful, both aneurysms were completely treated with SE in a single procedure. As a result, the bleeding was stopped. However, the patient died after 10 days because of subarachnoid hemorrhage and vasospasm. Others were cured completely and successfully by implanting the SE flow diverters, including 5 patients with ruptured aneurysms. Moreover, there were no patients who died because of the treatment of SE flow diverters.

\section{Conclusion}

In this review, the epidemiology, diagnostic method and effectiveness of different therapies is summarized and compared.

For the conventional treating strategies described here, the DED can be a replaced device of PED because of its dependable safety and effectiveness. Although the DED device presents comparable complication rates, morbidity, and angiographic outcome between the groups, anti-thrombogenic surface modification and improved fluoroscopic visibility of the DED did not make any improvements in regard to thromboembolic complications and fluoroscopic time, dose, and procedure time, respectively. Further research and larger observational studies are needed to find out the advantages of improved visibility and antithrombogenic surface modification.

The high technical success rate exhibits a significant improvement of SE flow diverter profile with easier navigation and deployment through a redesigned delivery system. The brand new Surpass Evolve flow diverter is likely to be an effective and efficient treating device with a favorable navigability and deployment profile. Though the short-term occlusion was successful, the efficacy of aneurysm occlusion needs to be proved in long-term follow-up studies. As a result, more research and more observation studies need to be done in the future.

\section{Reference}

1. Chapman AB, Rubinstein D, Hughes R, et al. "Intracranial aneurysms in autosomal dominant polycystic kidney disease." N Engl J Med 1992; 327: 916-20.

2. Gibbs GF, Huston J 3rd, Qian Q, et al. "Follow-up of intracranial aneurysms in autosomal-dominant polycystic kidney disease." Kidney Int 2004; 65: 1621-27.

3. Mariani L, Bianchetti MG, Schroth G, Seiler RW. "Cerebral aneurysms in patients with autosomal dominant polycystic kidney disease - to screen, to clip, to coil?" Nephrol Dial Transplant 1999;14: 2319-22.

4. Schievink WI. "Genetics of intracranial aneurysms". Neurosurgery 1997; 40: 651-62.

5. Connolly HM, Huston J 3rd, Brown RD Jr, Warnes CA, Ammash NM, Tajik AJ. "Intracranial aneurysms in patients with coarctation of the aorta: a prospective magnetic resonance angiographic study of 100 patients". Mayo Clin Proc 2003; 78: 1491-99.

6. Wiebers DO, Whisnant JP, Huston J 3rd, et al, and the International Study of Unruptured Intracranial Aneurysms Investigators. "Unruptured intracranial aneurysms: natural history, clinical outcome, and risks of surgical and endovascular treatment." Lancet 2003; 362: 103-10.

7. Batjer H, Suss RA, Samson D. "Intracranial arteriovenous malformations associated with aneurysms." Neurosurgery 1986; 18: 29-35.

8. Miyasaka K, Wolpert SM, Prager RJ. "The association of cerebral aneurysms, infundibula, and intracranial arteriovenous malformations." Stroke 1982; 13: 196-203.

9. Alg VS, Sofat R, Houlden H, Werring DJ. "Genetic risk factors for intracranial aneurysms: a metaanalysis in more than 116000 individuals." $\mathrm{Neu}$ rology 2013; 80: 2154-65.

10. Foroud T, Koller DL, Lai D, et al, and the FIA Study Investigators. "Genome-wide association study of intracranial aneurysms confirms role of Anril and SOX17 in disease risk." Stroke 2012; 43: 2846-52.

11. Kissela BM, Sauerbeck L, Woo D, et al. "Subarachnoid hemorrhage: a preventable disease with a heritable component." Stroke 2002; 33: 1321-26.

12. Bromberg JE, Rinkel GJ, Algra A, et al. "Familial subarachnoid hemorrhage: distinctive features and patterns of inheritance." Ann Neurol 1995; 38: 929-34.

13. Bromberg JE, Rinkel GJ, Algra A, Limburg M, van Gijn J. "Outcome in familial subarachnoid hemorrhage.” Stroke 1995; 26: 961-63.

14. Mackey J, Brown RD Jr, Moomaw CJ, et al, and the FIA and ISUIA Investigators. "Unruptured intracranial aneurysms in the Familial Intracranial Aneurysm and International Study of Unruptured Intracranial Aneurysms cohorts: differences in multiplicity and location." J Neurosurg 2012; 117: 6064.

15. Magnetic Resonance Angiography in Relatives of Patients with Subarachnoid Hemorrhage Study Group. "Risks and benefits of screening for intracranial aneurysms in first-degree relatives of patients with sporadic subarachnoid hemorrhage." $N$ Engl J Med 1999; 341: 1344-50.

16. Huttunen T, von und zu Fraunberg M, Frösen J, et al. "Saccular intracranial aneurysm disease: distribution of site, size, and age suggests different etiol- 
ogies for aneurysm formation and rupture in 316 familial and 1454 sporadic eastern Finnish patients." Neurosurgery 2010; 66: 631-38.

17. Rinne J, Hernesniemi J, Puranen M, Saari T. "Multiple intracranial aneurysms in a defined population: prospective angiographic and clinical study." Neurosurgery 1994; 35: 803-08.

18. Juvela S, Hillbom M, Numminen H, Koskinen P. "Cigarette smoking and alcohol consumption as risk factors for aneurysmal subarachnoid hemorrhage." Stroke 1993; 24: 639-46.

19. Shiue I, Arima H, Hankey GJ, Anderson CS, and the ACROSS Group. "Modifiable lifestyle behaviours account for most cases of subarachnoid haemorrhage: a population-based case-control study in Australasia." J Neurol Sci 2012; 313: 9294.

20. Longstreth WT Jr, Nelson LM, Koepsell TD, van Belle G. "Cigarette smoking, alcohol use, and subarachnoid hemorrhage." Stroke 1992; 23: 124249.

21. Klatsky AL, Armstrong MA, Friedman GD. "Alcohol use and subsequent cerebrovascular disease hospitalizations." Stroke 1989; 20: 741-46.

22. Knekt P, Reunanen A, Aho K, et al. "Risk factors for subarachnoid hemorrhage in a longitudinal population study." J Clin Epidemiol 1991; 44: 933-39.

23. Bonita R. "Cigarette smoking, hypertension and the risk of subarachnoid hemorrhage: a populationbased case-control study." Stroke 1986; 17: 83135 .

24. Longstreth WT, Nelson LM, Koepsell TD, van Belle G. "Subarachnoid hemorrhage and hormonal factors in women. A population-based case-control study." Ann Intern Med 1994; 121: 168-73.

25. Johnston SC, Colford JM Jr, Gress DR. "Oral contraceptives and the risk of subarachnoid hemorrhage: a meta-analysis." Neurology 1998; 51: 41118.

26. Zacharia BE, Hickman ZL, Grobelny BT, et al. "Epidemiology of aneurysmal subarachnoid hemorrhage." Neurosurg Clin N Am 2010; 21: 221-33.

27. Jakubowski J, Kendall B. "Coincidental aneurysms with tumours of pituitary origin." J Neurol Neurosurg Psychiatry 1978; 41: 972-79.

28. Jellinger K. "Pathology of intracerebral hemorrhage." Zentralbl Neurochir 1977; 38: 29-42.

29. Kassell NF, Torner JC, Jane JA, Haley EC Jr, Adams HP. "The International Cooperative Study on the Timing of Aneurysm Surgery. Part 2: surgical results." J Neurosurg 1990; 73: 37-47.

30. Vlak MH, Algra A, Brandenburg R, Rinkel GJ. "Prevalence of unruptured intracranial aneurysms, with emphasis on sex, age, comorbidity, country, and time period: a systematic review and metaanalysis." Lancet Neurol 2011; 10: 626-36.

31. Winn HR, Jane JA Sr, Taylor J, Kaiser D, Britz GW. "Prevalence of asymptomatic incidental aneu- rysms: review of 4568 arteriograms." Stroke 1983; 14: 121

32. Atkinson JL, Sundt TM Jr, Houser OW, Whisnant JP. "Angiographic frequency of anterior circulation intracranial aneurysms." J Neurosurg 1989; 70: 551-55.

33. Vernooij MW, Ikram MA, Tanghe HL, et al. "Incidental findings on brain MRI in the general population." N Engl J Med 2007;357: 1821-28.

34. Li MH, Chen SW, Li YD, et al. "Prevalence of unruptured cerebral aneurysms in Chinese adults aged 35 to 75 years: a cross-sectional study." Ann Intern Med 2013; 159: 514-21.

35. Müller TB, Sandvei MS, Kvistad KA, et al. "Unruptured intracranial aneurysms in the Norwegian Nord-Trøndelag Health Study (HUNT): risk of rupture calculated from data in a population-based cohort study." Neurosurgery 2013; 73: 256-61.

36. Chason JL, Hindman WM. "Berry aneurysms of the circle of Willis; results of a planned autopsy study." Neurology 1958; 8: 41-44.

37. International Study of Unruptured Intracranial Aneurysms Investigators. "Unruptured intracranial aneurysms - risk of rupture and risks of surgical intervention." N Engl J Med 1998; 339: 1725-33.

38. Inagawa T, Hirano A. "Autopsy study of unruptured incidental intracranial aneurysms." Surg Neurol 1990; 34: 361-65.

39. Meyer FB, Sundt TM Jr, Fode NC, Morgan MK, Forbes GS, Mellinger JF. "Cerebral aneurysms in childhood and adolescence." J Neurosurg 1989; 70: 420-25.

40. Storrs BB, Humphreys RP, Hendrick EB, Hoffman HJ. "Intracranial aneurysms in the pediatric agegroup." Childs Brain 1982; 9: 358-61.

41. Magnetic Resonance Angiography in Relatives of Patients with Subarachnoid Hemorrhage Study Group. "Risks and benefits of screening for intracranial aneurysms in first-degree relatives of patients with sporadic subarachnoid hemorrhage." $N$ Engl J Med 1999; 341: 1344-50.

42. Raaymakers TW. "Aneurysms in relatives of patients with subarachnoid hemorrhage: frequency and risk factors." MARS Study Group. "Magnetic Resonance Angiography in Relatives of patients with Subarachnoid hemorrhage." Neurology 1999;53: 982-88.

43. Ronkainen A, Hernesniemi J, Puranen M, et al. "Familial intracranial aneurysms." Lancet 1997; 349: 380-84.

44. Ronkainen A, Miettinen H, Karkola K, et al. "Risk of harboring an unruptured intracranial aneurysm." Stroke 1998; 29: 359-62.

45. Menghini VV, Brown RD Jr, Sicks JD, O'Fallon WM, Wiebers DO. "Clinical manifestations and survival rates among patients with saccular intracranial aneurysms: population-based study in 
Olmsted County, Minnesota, 1965 to 1995." Neurosurgery 2001; 49: 251-56.

46. Wiebers DO, Whisnant JP, O'Fallon WM. "The natural history of unruptured intracranial aneurysms." N Engl J Med 1981; 304: 696-98.

47. Wiebers DO, Whisnant JP, Sundt TM Jr, O'Fallon WM. "The significance of unruptured intracranial saccular aneurysms." J Neurosurg 1987; 66: 23-29.

48. Juvela S, Porras M, Poussa K. "Natural history of unruptured intracranial aneurysms: probability of and risk factors for aneurysm rupture." J Neurosurg 2000; 93: 379-87.

49. Juvela S, Poussa K, Lehto H, Porras M. "Natural history of unruptured intracranial aneurysms: a long-term follow-up study." Stroke 2013; 44: 2414-21.

50. Tsutsumi K, Ueki K, Morita A, Kirino T. "Risk of rupture from incidental cerebral aneurysms." $J$ Neurosurg 2000; 93: 550-53.

51. Brouillard AM, Sun X, Siddiqui AH, Lin N. "The use of flow diversion for the treatment ofintracranial aneurysms: expansion of indications." Cureus. 2016;8:e472.

52. Fiorella D, Lylyk P, Szikora I, et al. "Curative cerebrovascular reconstruction with the Pipeline embolization device: the emergence of definitive endovascular therapy for intracranial aneurysms." J Neurointerv Surg. 2009;1:56-65.
53. Wallace AN, Delgado Almandoz JE, Kayan Y, et al. "Pipeline treatment of intracranial aneurysms is safe and effective in patients with cutaneous metal allergy." World Neurosurg. 2019;123:e180-e185.

54. Akgul E, Onan HB, Akpinar S, Balli HT, Aksungur EH. "The DERIVO embolization device in the treatment of intracranial aneurysms: short- and midterm results." World Neurosurg. 2016;95: 229240.

55. Kallmes DF, Ding YH, Dai D, Kadirvel R, Lewis DA, Cloft HJ. "A new endoluminal, flowdisrupting device for treatment of saccular aneurysms." Stroke. 2007;38:2346-52.

56. Charlotte Zaeske, Lukas Goertz, Franziska Dorn, Bernd Turowski, Nuran Abdullayev, Marc Schlamann, Thomas Liebig, Christoph Kabbasch. "Comparative Analysis of the Pipeline and the Derivo Flow Diverters for the Treatment of Unruptured Intracranial Aneurysms-A Multicentric Study." World Neurosurg. (2020). https://doi.org/10.1016/j.wneu.2020.10.062.

57. V. Maus, W. Weber, A. Berlis, C. Maurer, S. Fischer. "Initial Experience with Surpass Evolve Flow Diverter in the Treatment of Intracranial Aneurysms." Clin Neuroradiol. https://doi.org/10.1007/s00062-020-00972-5 . 